\title{
Legacy of Lance M Optican: from math to medical science and back
}

\author{
Jeffrey D. Schall ${ }^{1}$. Aasef G. Shaikh ${ }^{2,3}$ \\ Published online: 25 May 2021 \\ (c) This is a U.S. government work and not under copyright protection in the U.S.; foreign copyright protection may apply 2021
}

More than one hundred basic and computational neuroscientists, clinicians, engineers, and their students attended a special satellite event before the 2018 Society for Neuroscience meeting in San Diego, California. The event was to honor the premiere computational neuroscientist and dear colleague, Lance M. Optican.

After earning a bachelor's degree in physics and biosystems analysis at the California Institute of Technology in 1972, Lance joined the Wilmer Eye Institute of Johns Hopkins University to work with David A. Robinson. David Zee explains, "[W]hen I [began] working with Lance, in about 1974, he [began] participating in our clinical patient ward rounds. ... For Lance, as was the tradition of our mentor, Dave Robinson, models and teaching clinicians about models were the way to help us understand our patients. [M]any studies with Lance, from various types of nystagmus to strabismus to saccadic and pursuit oscillations, which successfully took physiology and bioengineering to the bedside." His doctoral thesis focused on the computational physiology of primate rapid eye movements (saccades).

After landmark research on computational neuroscience of ocular motor adaptation in non-human primates, Lance moved a few miles south of Baltimore, to the National Institute of Mental Health, as a post-doctoral fellow with Fred Miles. Later, they both joined the Laboratory for Sensorimotor Research in the National Eye Institute. The chemistry was so good that Lance remained at NEI for rest of his career, becoming a tenure-track investigator in 1982.

This article belongs to the Topical Collection: Vision and Action Guest Editors: Aasef Shaikh and Jeffrey Shall

Aasef G. Shaikh

aasefshaikh@gmail.com

1 Visual Neurophysiology Centre, Department of Biology, Faculty of Science, York University, Toronto, ON, Canada

2 Department of Neurology, University Hospitals, Cleveland, $\mathrm{OH}$, USA

3 Neurology Service, Louis Stokes Cleveland VA Medical Center, Cleveland, OH, USA
Figure 1 shows a group photo of Lance Optican, David Zee, Fred Miles with their spouses and David Robinson.

Lance has mentored dozens of basic and clinical scientists from different countries. Many of his protégé are now successful academics. Opposed to any status quo, Lance enjoys working with fresh ideas, new perspectives, blue-sky thinking, and most importantly, logical explanations. He sought these characteristics in his students.

Lance's wife Donna helped him create a welcoming environment for new fellows. She was a gracious hostess for lab events and helped when new fellows joined his lab. She gave tours of D.C., helped them get cars or find housing. Lance almost always travelled to meetings with his wife. Donna was a great help, for example, visiting the Louvre for him while he was in meetings. Lance and Donna appears in a photograph shot in the historic library of the University of Pavia (Fig. 2). The meeting was held to honor Lance Optican in 2018.

One fellow, Pierre Daye, notes: "Lance is an empowering mentor. $[\mathrm{He}]$ gave me the opportunities to build and develop my own ideas. [He] told me once: 'I'm not looking for fellows that think like the mainstream research labs in Neuroscience. I want to work with people who look out-ofthe-box and can come with unusual ideas (and be prepared to defend them).' The counterpart of that is that if you have a freedom of thinking, you have the responsibility to defend yourself correctly when you present your results. [For] an SfN congress ... we prepared two companion posters ... I was very proud of the work and very happy (because I felt a bit safe) that Lance and I would present our work together. [But, Lance] left to take his plane back to DC. Everything went fine and ... I realized that spending that much time rehearsing with the LSR and Lance made me bulletproof with all the questions that others could have asked...".

Christian Quaia, another Optican-protégé and long-term colleague at LSR said: "For me, Lance's defining characteristic was his uncompromising adherence to the data. He never fell in love with a theory, even and especially his own, or built models based on how the brain would have been built by an engineer ... [W] hen the necessary data were not 


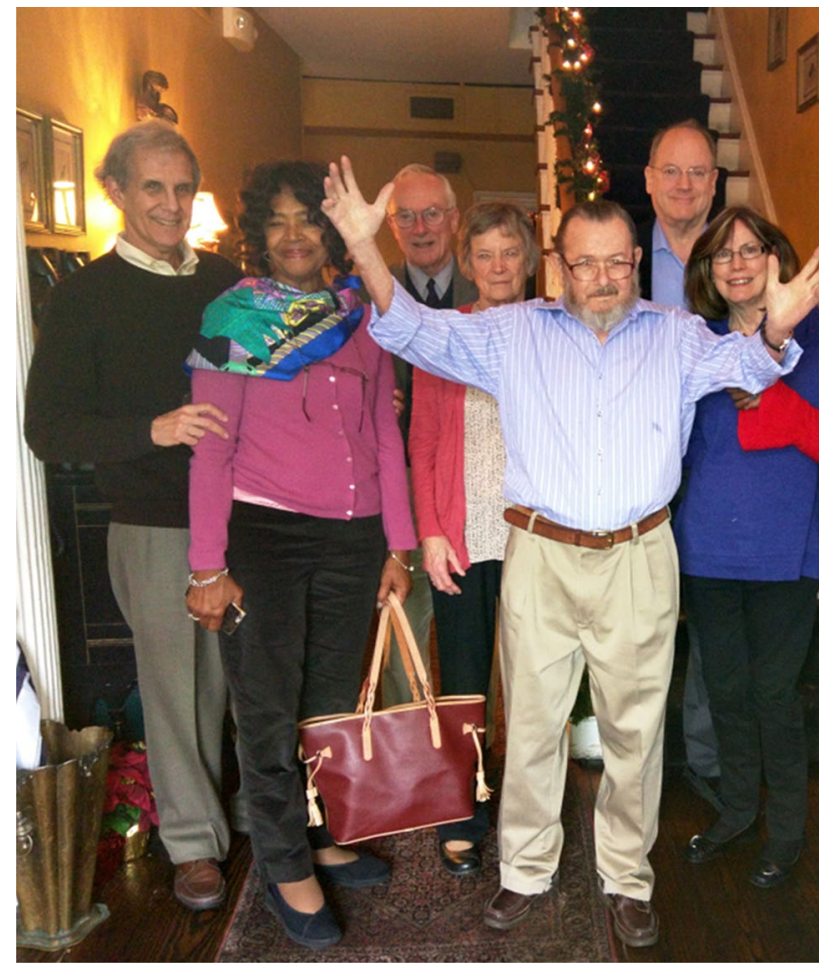

Fig. 1 Lance and Donna Optican (right) with David and Paulette Zee (left), Fred and Jennifer Miles (Center) celebrating the $90^{\text {th }}$ birthday of David Robinson (third from the right)

available, he collected his own. And from there he went wherever the data took him. Like a true Renaissance man, he used the depth and breadth of his technical knowledge to ... make sense of vast amounts of disparate ... anatomical, physiological, behavioral [data]. His other great gift was his

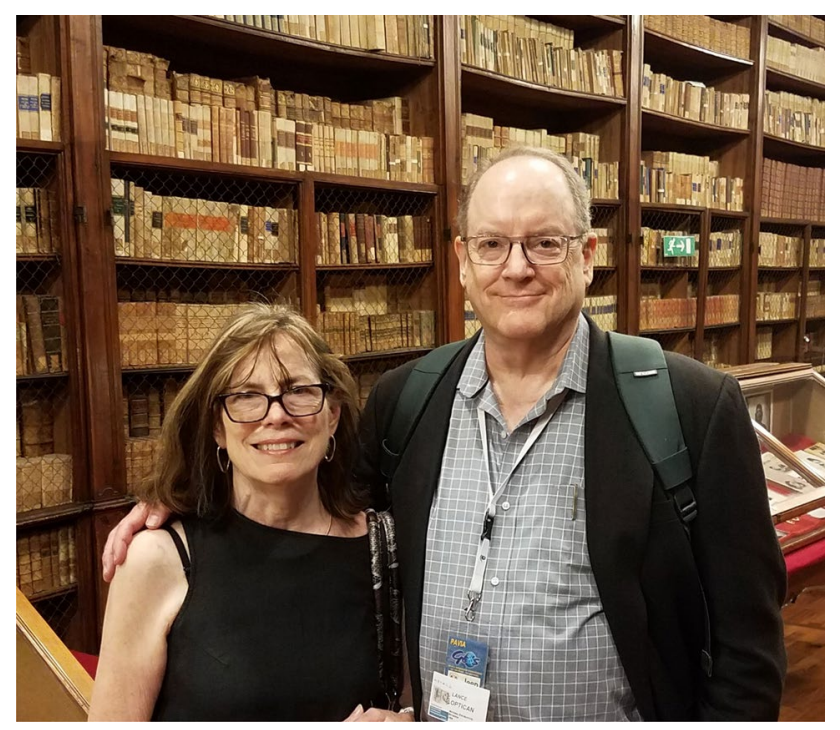

Fig. 2 Lance and Donna during their visit of historic library at the University of Pavia in June 2018 ability to explain complex concepts in simple terms ... to collaborate effectively with people who were not as mathematically savvy as himself. [W] hat most endeared him to those who knew him well was that he always took seriously his work, but not himself."

Lance could translate complex mathematical principles into simplified language that anyone can understand. He could also take a complex biological phenomenon and seamlessly generate a physiologically realistic mathematical model. Following his mentor, David A. Robinson, Lance showed the power of mathematical modeling to systems physiology and clinical neurosciences. Lance loved data and the insights gained through computational modeling. He also enjoyed poking fun at pretensions, even his own. We remember a Gordon Research Conference on Eye Movements at which, before he began speaking, he took a photo of the audience.

Lance's colleagues respected his abilities and values. Michael Goldberg, who wrote, "Lance is a force of nature", summarized Lance's intellectual rigor in the LSR, "He was always the most helpful person when you had a mathematical or theoretical problem, [but he had no] gradation in his criticism of papers and ideas-they were either OK or the stupidest thing he had ever seen." Barry Richmond shared the experience during discussions about how the brain works. "We would say incredibly stupid things, and then we'd think better of them and say, 'We'd better go for another walk!'” Optican remembered. Masahiko Fujita remarked, "Lance thinks very fast".

R. John Leigh remembers, "[W]henever I hit a conceptual bump, I would ask Lance for advice. For example, in 2001, we found that we [could] induce high-frequency saccadic oscillations in a patient with a large midline cerebellar lesion that involved the fastigial nucleus, [which contradicted] models for saccadic oscillations ... [A]t the Society for Neuroscience meeting ..., I [asked] Lance .... "Isn't this a problem for your model?" Lance responded: "Hmm...just give me a few minutes to think about this" and went off to his hotel room. After an hour or so, he emerged with the essence of a new model (a rough sketch on the hotel's paper napkin, Fig. 3) to account for saccadic oscillations, based on the inherent connectivity of brainstem burst neurons. Thus, ... born of Lance's imagination ... was an influential neuromimetic model that has opened up new ways to conceive and even treat saccadic oscillations. Lance's brilliant mind and warm collegiality have made him a great collaborator and translational researcher."

The current volume subtends the scope of Lance's interests, philosophy, and career and honors his legacy. Spanning the visual pathway from input to output, diverse publications link mathematical models with basic neurophysiology, describe new behavioral neuroscience observations, and characterize clinical neurology phenomena. The 


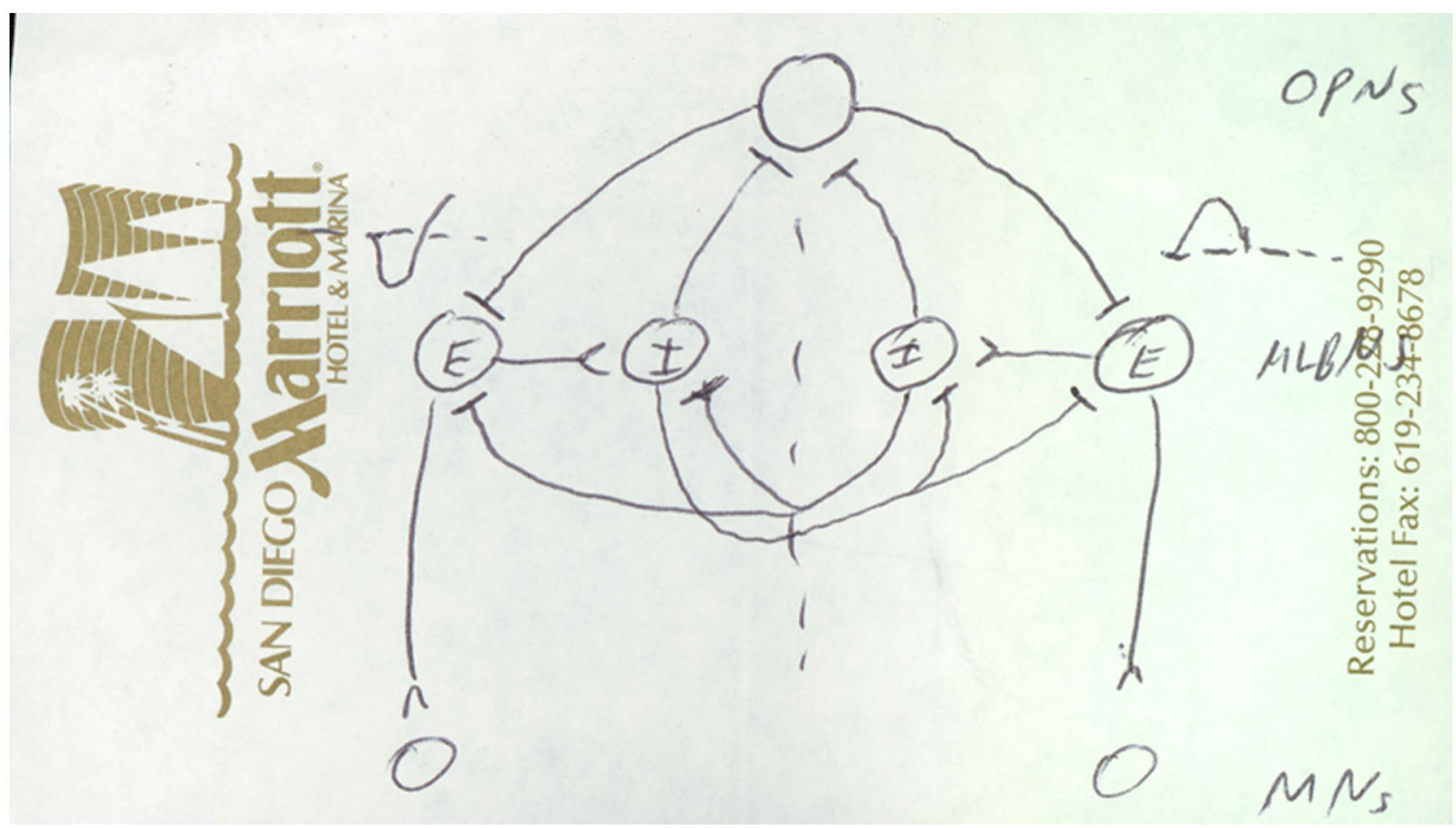

Fig. 3 Lance instantly constructed a model accommodating a new clinical finding

contributions range from pure computational models to models of single neuron recordings or of disease phenomenology. The diversity of authors, reflecting that of Lance's students and colleagues, come from various parts of the world, making the collection not only multidisciplinary but also multicultural - just what Lance admires and enjoys.
"And now to stop. To have more fun. To travel and enjoy. A wondrous switch for Lance who was the LSR's best boy." 